Vol. 2, No. 3, 2020

Review Article

\title{
Online Marketing and the Performance of Small-Scale Enterprises in Nigeria: A Study of Selected SMEs in Ikeja, Lagos State, Nigeria
}

\author{
Oyedele Ola Olusegun*, Oworu Oyefemi Olympus and Adbulganiyu Ibrahim Olakunle \\ Federal University of Agriculture, Abeokuta, Ogun State, Nigeria \\ olacollins2014@gmail.com; oworufemi@gmail.com; abdulganiuibraheem@gmail.com \\ *Correspondence: olacollins2014@gmail.com
}

\begin{abstract}
Received: 23 $3^{\text {rd }}$ April 2020; Accepted: 19 $9^{\text {th }}$ July 2020; Published: $1^{\text {st }}$ August 2020
Abstract: The study investigated Online Marketing and the Performance of Small and medium scale enterprises in Ikeja Local Government Area of Lagos State. Survey research design was employed for the study where 142 respondents (sample size) from the selected total estimated population of 221 SMEs for the study area and were gathered using structured questionnaire. Their responses were tested using appropriate statistical tools of SPSS package using the ANOVA, the correlation, and the regression too. Our study revealed that the Online Marketing affected the performance of SME positively which has allowed youths to be self-employed and created economic growth and regional development. Therefore, the study recommended that solving the performance of SME development can be single handedly done using Online Marketing. Hypothesis one shows correlation ( $r$ ) value = $66.6 \%(0.666)$, at the $P$ value of $<0.05$, which shows that the regression model was fit. Hypothesis two shows that $R^{2}$ of 0.452 , and value of $P>0.05$, adjusted $R^{2}=0.446, R^{2}$ measures the percentage of variation in the dependent variable caused by variation in the independent variable. This research provides recommendations extracted from findings that, businesses need to develop indigenous technology; new products or processes based on innovations; seek, commercialize or exploit new technology ideas to meet market needs, customer expectations/preferences and consumer demands and identify market opportunities.
\end{abstract}

Keywords: Online Marketing; SMEs; Performance; Lagos State; Business Performance

\section{Introduction}

Businesses are looking to new technologies to meet their unique business requirements and position themselves to take advantage of global changes in business activities. Businesses, both large and small, need the information to succeed in today's rapidly changing environment; they need to be able to process data/datum and use information effectively when conducting their day-to-day operations. The growth of the Internet has opened up a vast arena, providing more opportunities for businesses, particularly from small to medium-sized enterprises (SMEs) to sell their products and services to a larger audience than they would have been able to afford to reach using the traditional methods. An extensive literature search reveals that many changes in firms today have been technology-driven information technology (I.T) is

Oyedele Ola Olusegun, Oworu Olufemi and Adbulganiyu Ibrahim Olakunle, "Online Marketing and the Performance of Small-Scale Enterprises in Nigeria: A Study of Selected SMEs in Ikeja, Lagos State, Nigeria", Annals of Contemporary Developments in Management E HR (ACDMHR), Print ISSN: 2632-7686, Online ISSN: 2632-7694, pp. 15-24, Vol. 2, No. 3, 1st August 2020, Published by International Association of Educators and Researchers (IAER), DOI: 10.33166/ACDMHR.2020.03.003, Available: http://acdmhr.theiaer.org/archive/v2/v2n3/p3.html. 
really changing the whole nature of the business transaction between consumers and suppliers of goods and services.

Online marketing deploys internet to deliver promotional marketing information to consumers that include email marketing, search engine marketing, social media marketing, many types of display advertising (including web banner advertising), and mobile advertising. Like other advertising media, online advertising constantly involves both a publisher, who integrates advertisements into its online content and an advertiser, who provides the advertisements to be displayed on the publisher's content (Amruta, 2014). Social media marketing is the type that uses online communities, social networks, blog marketing and more. It is the latest "buzz" in online marketing. Any website which allows user to share their content, opinions, views and encourages interaction and community building can be classified as social media. Some other popular social media sites are Facebook, YouTube, Twitter, Instagram, my space, stumble upon, Scribe, Flicker, etc. Global firms have recognized Social Media Marketing as a potential marketing platform, with innovations to power their advertising campaign with social media marketing (Neti, 2011). Social networking provides small businesses with multiple opportunities to build closer and more profitable relationships with ultimate customers.

Consequent to this background, this research aims at examining the impact of online marketing on the performance of SMEs in Ikeja Metropolis within Lagos-Nigeria with reference to SMEs.

\subsection{Statement of Research Problem}

Online marketing has changed and is still changing the way business is conducted around the globe. The commercialization of the internet has assisted online marketing to become one of the most promising avenues for inter-organizational business processes. Online marketing started with various means of relationship within the business processes. In Nigeria, many small and medium enterprises are investing and showing more and more interest in the Internet/online marketing business. To survive in today's challenging environment, it is important that SMEs be competitive and resilient. Hence, the main problem of this study is to determine the effect of online marketing applications on the firms' success in the small and medium enterprises arena.

In today's media-driven environment, it is essential that small firms understand the various social media handles such as Facebook, Twitter, Instagram, etc., and the strategies behind using social media for growing their business. Unfortunately, many small firms do not have a social media strategy (Adegbuyi \& Akinyele, 2015). Moreover, one of the most salient areas in which SMEs have challenges is in marketing the inability to carry out effective marketing activities for the firms. Social media has significantly changed the relationships between customers and firms by creating and allowing two-way communication. Social media tools assist companies in communicating with individual consumers, which are, in turn, help, establish long-term relationships. Social media tools such as forums, blogs, or chat rooms create an interactive dialogue for firms to interact with consumers. However, consumers can produce information about an organization and educate other consumers about products, brands, services, and more (Cox, 2012).

Suffice to say that online advertising in the major sites in Nigeria occupies significant position, the effectiveness of online advertising comes from whether consumers are interested in clicking and watching, but the reality is that most internet consumers ignore online advertising and how to attract the attention of consumers has become a very important issue. In practice, different forms of advertising can be designed to attract consumers, such as pop-up ads, button ads, advertising couplet, floating ads, full-page advertising, and so on. Especially for SMEs, due to restrictions on marketing resources, news, advertising, large-scale promotional activities, they have less chance of publicity, so website promotion via the internet means is much more important for them than big ones (Njau \& Karugu, 2014). Thus, this study investigates 
the relationship between online advertising and small and medium scale businesses performance in Ikeja Metropolis in Lagos, Nigeria.

\section{Literature Review}

\subsection{Online Marketing}

The need for social interactions between human beings has always existed, resulting in the creation of platforms or networks for either informal or formal social interactions. Social networks are studied across a wide range of disciplines from sociology to science and technology. Several studies and literature have indicated a relationship between online marketing and sales. Online marketing is able to reach new customers and provide personalized communication to the customers, hence increasing awareness and sales (Jain 2014; Jagongo \& kinyua 2016). Online marketing combines the internet's creative and technical tools, including design, development, sales and advertising. Online is where the eyeballs are and so that's where your business needs to be (Susan, 2018). According to strategy analytics in 2017 online advertising was up $12 \%$ of overall spending on advertising, this kind of growth explains why online marketers are constantly devising new internet marketing strategies in the hopes of driving more traffic to their websites \& to their offline stores and making more sales (Susan, 2018).

\subsection{Social Media Marketing}

Social media marketing is marketing using online communities, social networks, blog marketing and more. It is the latest "buzz" in marketing. Global companies have recognized Social Media Marketing as a potential marketing platform, utilized them with innovations to power their advertising campaign with social media marketing (Neti, 2011). Social media marketing enables companies to achieve a better understanding of customers' needs to build effective relationships (Mozammel et al., 2018; Cox, 2012). Social media marketing (SMM) takes advantage of social networking to help a company increase brand exposure and broaden customer reach. The goal is usually to create content compelling enough that those users will share it with their social networks (Cox, 2012).

Via gathering media allows organizations to function integrated marketing behavior with to a great extent a smaller amount attempt and detriment than before and organizations that utilization and instigate the newest shared media technologies look as if to outshine their competitors with extra reimbursements like sink outlay and enhanced efficiencies (Eisenfeld and Fluss, 2009; Harris and Rea, 2009). Accordingly, Parveen, Jaafar and Ainin (2016) affirmed that get-together media treatment has an assured effect on organizations' performance, apropos charge reduction, better client relations, and enhanced in order accessibility. Furthermore, get-together media tin exhibit a major effect on organizations in digital marketing and promotion, usage buyer once-over issues, mining innovative ideas, and edifice purchaser relations. Cost-effectiveness of communal media be able to be painstaking as one of the source factors that are allied to shared media procedures in organizations (Kaplan \& Haenlein, 2010). Shared media tin similar be second-hand by miniature and medium-sized enterprises (SMEs) proper to its muffled expenditure and smallest procedural necessities (Derham, Cragg and Morrish., 2011).

Therefore, gathering media practice continues to increase fundamentally between businesses and is fast revolving to a crucial occupational management phenomenon. especially comparing with established message tools, firms know how to engage through gathering media in an apt and point end-consumer link at moderately muted cost, and top levels of efficiency (Parveen et al., 2016), this outlay operative quality of party media attracts generously proportioned transnational organizations, SMEs, non-profit organizations, and lawmaking agencies (Kaplan \& Haenlein, 2010). 


\subsection{Online Advertising}

Online Advertising is a powerful tool for advertisers and organization used for advertisement as people are now spending more time online; the Internet became another channel via which companies can market their offerings successfully. Because of the Internet's versatility, it will give an organization the opportunity to reach and interact with its target market. Companies can now produce an Integrated Marketing Communication (IMC) campaigns that exclusively target the desired customer more successfully with less cost as compared to traditional communication efforts (Amruta, 2014). Online campaigns give organization new abilities to the business via reach (huge number of users. relevance (full information is provided about offerings) and return on investment (ROI).

Online advertising is advertisement done on the internet and consists of advertisement placed on search engine pages, embedded in e-mails, affiliate marketing and other mediums businesses and advertisers use the internet. The primary aim is to acquire prospective customers to act immediately through clicks (The Saylor Foundation, 2017). Affiliate marketing is a rising form of online advertisements where a user or website promotes an online retailer and earns commission on leads generated for the online retailer. Innovative advertising formats like social media advertising for instance Facebook, Twitter enable companies to get in direct contact with users. Compared to the up to then purely one-sided communication within traditional mass media, online advertising enables a direct reaction from users towards the advertising companies. It can even be 'one-to-one communication' (Evans, 2009). Moreover, direct actions (e.g. purchasing actions) by users are possible which is attractive for companies with e-commerce activities. Another crucial aspect is the costs for online advertising.

\subsection{SME Performance}

Typically, performance is ultimate outcome expected in every business activity (Muhammad et al., 2019; Ahmed et al., 2018; Galdeano et al., 2018; Ahmed, Mozammel \& Ahmed, 2018; Roespinoedji et al., 2019). SME performance is the total performance of the firm and is showed by the aggregate of performance of finance, marketing, and human resource functions of the organization in a given time. Firms formulate goals and objectives to be achieved within a given time frame. Performance measures the organizations' effectiveness against these set objectives. Thus, organizational performance refers to the ability of an organization to attain its goals such as high-profit margin, product quality, and larger market share, better financial results at a stipulated time and by applying the relevant strategy. Organizational performance has many dimensions which may be difficult to quantify (Rowley, 2011) opines that, both financial and nonfinancial indicators have been used to measure performance. The financial indicators were sales growth and percentage profit margin. In the service industry, employee productivity has been used as a measure of performance (Mishra, 2008).

Gavrea, Ilies and Stegerean, (2011) SME performance shows the actual output or results of an organisation as measured against its proposed outputs (or goals and objectives). It is one of the most important variables in the field of management research today. Although the concept of SME performance is very common in academic literature, its definition is not yet a universally accepted concept. Richard et al, (2006) view SME performance as comprises three specific areas of firm outcomes: (a)financial performance (profits, return on assets, return on investment, etc.), (b) product market performance (sales, market share, etc.); and (c) shareholder return (total shareholder return, economic value added, etc.). Waiganjo, Mukulu \& Kahiri, (2012) note that SME performance may be assessed in terms of its multiple objectives of profitability, employee satisfaction, productivity, growth among many other objectives. Proponents of the balanced score card performance management system have suggested a broader performance appraisal approach that recognizes both the financial and non-financial measures including sales, profitability, return on investments, market share, customer base, product quality, innovation and company attractiveness. Richard et al, (2009) explains that SME performance includes the actual output or 
results of fims as measured against its intended outputs (goals and objectives). Kunze (2013), has defined SME performance as consisting of both SME and operational dimensions of performance.

\subsection{Online Marketing and SME Performance}

Taleghani, Akhlagh and Sani (2013), found that Digital-marketing has direct effect on performance of Pistachio-exporting companies in Iran. The firms achieve higher assets turnover, more export share, sales and export growth, more client attraction and retention in export markets, and thereby improved on their financial and non- financial performance. The internet supports the firms' distributors and agents in enhancing their marketing activities and filling the knowledge gap on their products, promotions, price and competition to their clients. The marketing aspect of SMEs is different to that of large corporations, thus making online marketing a greater challenge for them (Lipiamen \& Karjaluoto, 2013).

Small businesses are less likely to be successful in the adoption of online marketing compared to large businesses because they have limited resources and knowledge (Barnes et al., 2012). A Facebook research indicated that Kenyan entrepreneurs are some of the most active small businesses that generate revenue through advertisements on Facebook. Currently, a number of SMEs have embraced online marketing and it would be important to know its impact in terms of sales growth which translates to profitability. Online marketing remains an alternative for the SMEs to reach the market to provide awareness about their goods and services. SMEs need to know the digital techniques to use and their how to maximize customer reach towards better competitiveness (Olonade, 2017).

A study by Alford (2010) argues that successful online marketing is indispensable due to the extremely competitive tourism market. Small rural businesses need to improve their online web presence through effective search engine optimization. He argues that a business owner should know which keywords to include so that they are able to improve the company's search engine results. He suggests that internal and external links are vital, and that data should be kept up to date as a website is a customer's first impression of a company. McLaren (2011) recommends that the Midlands Meander Association and its members should utilize electronic media more effectively by establishing shared links to assist with marketing between members. The study also proposes the use of a search engine optimizer to increase the number of responses from customers. In addition, the study notes the value of social media and how the members could boost word of mouth through connections with tourists on Facebook, Twitter, and YouTube.

\subsection{Social Media Marketing and Customer Satisfaction}

Therefore, common media in big business would be a best-fit theory as it helps to position the direct customers in effect and businesses would be gifted to split the subject matter of their foodstuffs and armed forces approximately instantaneously (Derham et al., 2011). Patron satisfaction agency that to execute patron needs and requests throughout good/service period, compliant to re-purchasing and client piety (Anton, 1996). Similarly, public media know how to be second-hand for concern with customers, in this manner contributing to buyer knowledge and being paid purchaser participation (Tikkanen, Hietanen and Henttonen, 2009). Also, Jackson (2011) confirmed that at slightest partially of chirp and Facebook users avowed that they had be converted into extra expected to chat about, put in a good word for or exchange a company's food after they began next the business on shared media. Accordingly, Kimani (2015) acknowledged that group media marketing has a large amount appreciate to the family as it allows employees to tie with the clients, in particular the ones in numerous geographic zones, and it helps organizations to engage inapt and blunt end-consumer connection at plausibly sorry for yourself outlay and superior ranks of efficiency further than bottle be attained with the supplementary conventional exchange of ideas tools. 


\subsection{Online Advertising and Performance}

Consumers do refer to various mediums to get awareness, but the highest preference is being given to online media. Online media incorporates blogs, online PR, Window displays, banner ads, etc. And consumers today are more exposed to these forms of online advertising as compared to advertising through other mediums. Majority of consumers believe that companies should use online activities in their marketing efforts. Since online activities facilitate good access and higher reach to the customers, companies must take this advantage by incorporating online advertising in their marketing strategy (Amruta, 2014).

\subsection{Theoretical Findings: Social Network Theory}

Social Network Theory provides SMEs with insights on the social ties that exist between individuals, organizations or groups. It views social relationships in forms of nodes and ties (York University, 2005). The individuals are represented in the form of the nodes, and the relationships between individuals are represented by the tides. In its simplest form, it studies the relationship between nodes and ties. It looks at the ability of owners to get access to resources not under their control in a cost-effective way through networking. It provides value to businesses by allowing them access to social resources that are embedded within a network (e.g., social media). Parker and Alstyne (2011), add that digital platforms are characterized by network effects and include Desktops, PDAs, network Switches, Multimedia, and mobile devices like smartphones and ERP systems to link the demand side to the supply side of businesses. Freeman (2006) studies social networks as structures made up of individuals connected by interdependencies, including common interests, friendship, business communities or even dislikes.

Social networking sites such as Twitter, LinkedIn, My Space, and Facebook have proved to be popular online activities in relation to time spent (Nielsen, 2010). According to Pradiptarini (2011), Facebook is the most common social media site followed by Twitter, LinkedIn, MySpace and YouTube in popularity. Social media has changed the strategies, and tools firms use to communicate, emphasizing. The widespread acceptance of digital marketing practices have greatly contributed to the personalization of marketing where commercial entities progressively link with individual clients and users and gaining feedback on a one-to-one basis. Social media has therefore, become significant as a means of internet marketing given its wider adoption.

\section{Research Method}

This study adopted quantitative data analysis for this study; the survey research design was employed. The scope of the study covers Ikeja Local Government Area of Lagos state, Nigeria. The respondents who are owners of businesses in the areas were purposively randomly selected in order to accomplish the objective of the study. Data collected was through the primary method using a field survey of firms. A questionnaires instrument was designed using five-point likert scale with personal interview based on the questions in the questionnaire which was most effective due to time constraints. A sample of 142 respondents was taken from the total population of 221 of small and medium enterprises within the study area using random sampling method of Marcor S.S (2019) Calculator and Raosoft (2019) calculator based on reports of the number of small and medium businesses in the study area and approximately $85.6 \%$ of the administered questionnaires were retrieved. Both dependent and independent variables of the operationalized construct were measured by two (2) items, each validated by different authors found in extant literature. A pilot study was also carried out for the research instrument's content validity alongside a split half reliability test results 0.734 and 0.864 , respectively showed that the research instrument is reliable (Garson, 2009). 


\subsection{Data Analysis and Interpretation}

Pearson Product Moment Correlation via SPSS 20.0 was used to test the research hypotheses and analyze the dependent and independent variables.

\subsection{Hypotheses}

\subsubsection{Hypothesis One}

$\mathrm{H}_{0}$ : There is no significant relationship between social media marketing and customer satisfaction SME's.

$\mathrm{H}_{1}$ : There is a significant relationship between social media marketing and customer satisfaction SME's.

Table 1: Correlations of Social Media and Customer Satisfaction

\begin{tabular}{llll}
\hline & & $\begin{array}{l}\text { Social } \\
\text { Marketing }\end{array}$ & $\begin{array}{c}\text { Media Customer } \\
\text { Satisfaction }\end{array}$ \\
\hline \multirow{3}{*}{ Social Media Marketing } & Pearson Correlation & 1 & $.666^{* *}$ \\
& Sig. (2-tailed) & & .000 \\
& N & 122 & 122 \\
& Pearson Correlation & $.666^{* *}$ & 1 \\
Customer Satisfaction & Sig. (2-tailed) & .000 & \\
& N & 122 & 122 \\
\hline
\end{tabular}

**Correlation is significant at the 0.01 level (2-tailed).

Table 4.1.1 above explains the degree of association (relationship) between social media marketing and customer satisfaction. The result shows a positive and high degree of association between social media marketing and customer satisfaction since Pearson correlation coefficient is 0.666 . Also the correlation co efficient test value 0.000 is less than 0.01 (Sig. level). Hence, it implies that as social media marketing increases in customer satisfaction also increase.

\subsubsection{Hypothesis Two}

$\mathrm{H}_{0}$ : Online advertising has no impact on competitiveness in SME's.

$H_{1}$ : Online advertising has impact on competitiveness in SME's.

Table 2: Model summary of Online Advertising and Competitiveness

\begin{tabular}{ccccc}
\hline Model & $\mathrm{R}$ & $\mathrm{R}$ Square & Adjusted R Square & Std. Error of Estimate \\
\hline 1 & $0.696^{\mathrm{a}}$ & 0.452 & 0.446 & 1.703 \\
\hline \multicolumn{2}{c}{ a. Predictors: (Constant), Online advertising, b. Dependent variables: Competitiveness }
\end{tabular}

Table 3: ANOVA of Online Advertising and Competitiveness

\begin{tabular}{llllll}
\hline Model & Sum of Squares & Df & Mean Square & F & Sig \\
\hline 1 Regression & 63.476 & 1 & 63.476 & 21.897 & $0.000^{\mathrm{b}}$ \\
Residual & 458.024 & 158 & 2.899 & & \\
Total & 521.500 & 159 & & & \\
\hline
\end{tabular}

a. Predictors: (Constant), Online advertising, b. Dependent variables: Competitiveness

Table 4: Coefficients of Online Advertising and Competitiveness

\begin{tabular}{|c|c|c|c|c|c|c|c|c|}
\hline \multirow{3}{*}{ Model } & & & \multicolumn{2}{|c|}{ Unstandardized Coefficients } & \multirow{2}{*}{$\begin{array}{l}\text { Standardized Coefficients } \\
\text { Beta }\end{array}$} & & \multirow[t]{2}{*}{$\mathrm{T}$} & \multirow[t]{2}{*}{ Sig. } \\
\hline & & & B & Std. Error & & & & \\
\hline & 1 & (Constant) & 10.617 & 1.504 & & 7.061 & & 0.000 \\
\hline \multicolumn{3}{|c|}{$\begin{array}{l}\text { Online } \\
\text { Advertising }\end{array}$} & 0.396 & 0.085 & 0.349 & 4.679 & & 0.000 \\
\hline
\end{tabular}

a. Dependent Variable: Competitiveness

The result from the model summary table revealed to what extent does the variance in Online advertising can be explained by competitiveness is $45.2 \%$, i.e. ( $\mathrm{R}$ square $=0.452$ ). The ANOVA table shows 
the Fcal 21.897 at 0.000 significant level. The table shows that competitiveness is significantly achieved through online advertising.

The significance level below 0.01 implies that statistical confidence of above $99 \%$. This implies that online advertising has a significant positive competitiveness. Therefore the decision we reject the null hypothesis (Ho) and accept the alternative hypothesis (H1).

\section{Discussion of Findings}

This study empirically investigates the effect of Online Marketing on the Performance of SMEs in Ikeja Local Government Area, Lagos State. Shreds of evidence show how social media marketing and online advertising affects and influence customer satisfaction and competitiveness of SMEs, specifically small and medium businesses, in the study area in Lagos State, Nigeria.

The result of hypothesis test one (1) shows that there is a significant and positive relationship between social media marketing and customer satisfaction among SMEs in Ikeja, Lagos State $(R=0.666, R 2=0.423$, $\mathrm{P}=0.000<0.05)$. This outcome of the study is explained on the grounds that social media marketing applications like Facebook, Whatsapp, Instagram helps SMEs reach their targeted audiences, and it provides cheap communication with customers. When they gather information through social media marketing, they are upgrade their plans and offer to attract more customers. Besides, adoption of social media marketing is associated with customer acquisition, retention and influences customer brand loyalty Yasmin, Tasneem \& Fatema (2015), and Erdogmus \& Cicek (2012). The outcome shows that firms utilize these online marketing innovations to experience increasing demand from satisfied customers.

The outcome from the test of hypothesis two (2) shows that there is a significant and positive relationship between online advertising and competitiveness of SMEs $(\mathrm{R}=0.696, \mathrm{R} 2=0.452, \mathrm{P}=0.000<0.05)$. This finding is found to be consistent with evidence found in previous studies Onyago (2016); Kithinji (2014). It revealed that online advertising offers more benefits than traditional marketing through content and ads that best matches consumer interests. More importantly, it provides a new means to reach customers and promote products and services via e-mails, display advertisements, and online content as well as effective in mitigating increase competition. Finally, findings show that online advertising has the strongest effect on competitiveness as a measure of SMEs' performance.

\section{Conclusion}

The concept of online marketing is a crucial tool for businesses that are positioned to maximize the opportunities from digitalization, growing online presence and mobile phone usage to boost their competitiveness in terms of market share, sales growth, customer patronage, customer retention, customer brand loyalty and market reach. This study has significant implications for business owners, digital marketing/technology space and entrepreneurial ecosystems.

The results revealed that social media marketing, e-mail marketing and online advertising, significantly affect competitiveness and sales growth, respectively. Finally, it is believed that this study has extended previous knowledge and pieces of evidence in the existing literature on business, entrepreneurship and management.

\subsection{Recommendations}

This study provides recommendations extracted from the findings, thus the recommendations make explicit the implications of the findings to business owners and policymakers.

First, businesses should develop plans and create a budget for exploiting digital marketing tools and applications to enjoy its superior benefits over traditional marketing; reach target customers better, promote products and services via e-mails, display advertisements, mobile apps, search engine 
optimization (SEO) and search engine marketing (SEM) \& online contents and boost their market share; effectively mitigating increasing competition and maximize SMEs potential access to new markets.

Second, businesses should possess up-to-date social media profiles to engage customers by selling relevant contents; connect \& communicate with customers to assess whether product/service meet their expectations; increase customer base alongside influencing customer acquisition, brand loyalty and retention; to build customer trust and upgrade their plans and offers to attract more customers and keep them updated all the time.

Third, the use of web analytics to draw insights from digital data is quintessential. SMEs should leverage on analytics tools to monitor web traffic; measure the overall effectiveness of their online marketing efforts as well as make significant improvements to optimize performances.

Finally, online marketing should be a key area of interest for emerging entrepreneurs, tech enthusiasts, startup ecosystems and established businesses. Digital skills upgrading should be adopted to update business owners' skills and digital marketing benefits awareness to facilitate business and economic growth. The government and institutions (private sector) should initiate training and capacity building programs to assist SMEs owners as well as their employees acquire digital marketing skills, which would boost overall economic growth.

\subsection{Limitations and Suggestion for Further Studies}

A number of creative methods (in-depth interviews, case study and so on) could be used in the future for research purposes. Also, the study mainly focused on SMEs; future researches could to investigate more large firms and industry to determine if the findings will be similar. Panel data, case study or focus interviews could be used in future research to overcome the limitations of the primary data obtained through questionnaires like time spent on designing, coding, and analysis of research instruments and data. Finally, future studies on online marketing should look into the constraints behind SMEs' adoption of online marketing tools and applications.

\section{References}

Adegbuyi, O.A., Akinyele, F.A. \& Akinyele, S.T., (2015). Effect of social media marketing on small scale business performance in Ota-metropolis, Nigeria. International Journal of Social Sciences and Management, 2(3), 275- 283.

Ahmed, U., Mozammel, S., \& Ahmed, H. (2018). Performance on the road: examining the critical role of training effectiveness amongst the blue-collar employees in Bahrain. Asian Journal of Empirical Research, 8(9), 342-351.

Ahmed, U., Shah, S. A., Qureshi, M. A., Shah, M. H., \& Khuwaja, F. M. (2018). Nurturing innovation performance through corporate entrepreneurship: The moderation of employee engagement. Studies in Business and Economics, 13(2), 20-30.

Alford, P. 2010. Be internet savvy to boost business. Farmers Weekly, (online), 152 (14):77 Available: http://search.proquest.com/docview/340311177?accountid=10612>

Amruta V. P. (2014). Study of the effectiveness of online marketing on integrated marketing communication. Unpublished. M.Phil Dissertation. School of Management, D.Y. Patil University, Navi Mumbai.

Cox, S., (2012). Social Media Marketing in a Small Business. Retrieved from: https://docs.lib.purdue.edu/cgi/viewcontent.cgi? article=1012\&context=cgttheses.

Derham, R., Cragg, P., \& Morrish, S. (2011). Creating value: An SME and Social Media. Paper Presented at the Pacific Asia Conference on Information Systems, 59, 1-9.

Evans, D. S. (2009). The online advertising industry: economics, evolution, and privacy. The Journal of Economic Perspectives, 23(3), 37-60.

Freeman (2006). Retail Management: Offline and Online Perspective, Lagos: Pumark Nigeria Limited Educational Publishers.

Galdeano, D., Ahmed, U., Fati, M., Rehan, R., \& Ahmed, A. (2019). Financial performance and corporate social responsibility in the banking sector of Bahrain: Can engagement moderate?. Management Science Letters, 9(10), 1529-1542. 
Jagongo, A. \& Kinyua, C. (2013). The social media and entrepreneurship growth. International Journal of Humanities and Social Science, 3(10), 213-227.

Kaplan, A. M., \& Haenlein, M. (2010). Users of the world, unite! The challenges and opportunities of Social Media. Business Horizons, 53(1), 59-68.

Kimani, E. (2015). Role of social media marketing on organisational performance in Kenya. Journal of Business and Management, 17(1), 101-105.

Lipiainen, H. \& Karjayluoto, H. (2013). Are SMEs falling behind in digital marketing development? Unpublished, Jyvaskyla University.

McLaren, L. (2011). Critical marketing success factors for sustainable rural tourism routes: a KwaZulu-Natal stakeholder perspective (online). MPhil dissertation, University of Pretoria.

Mishra, A.K. (2008). Marketing to and serving customers through the internet: an overview and research agenda. Journal of the Academy of Marketing Science 30, 286-295

Mozammel, S., Ahmed, U., Slade, H., \& Zaman, F. (2018). Digging Deep in StudentsEngagement in Bahrain: Contributions From Academic Self-Efficacy and Academic Resilience. International Journal of Management and Business Research, 8(1), 136-147.

Muhammad, K., Saoula, O., Issa, M., \& Ahmed, U. (2019). Contract management and performance characteristics: An empirical and managerial implication for Indonesia. Management Science Letters, 9(8), 1289-1298.

Neti, S. (2011). Social Media and Its Role in Marketing. International Journal of Enterprise Computing and Business Systems, 1(2), 1-16.

Njau, J. N \& Karugu, W. (2014). Influence of e-marketing on the performance of small and medium enterprises in Kenya: Survey of small and medium enterprises in the manufacturing industry in Kenya. International Journal of Business and Law Research, 2(1), 62-70.

Olonde J. O. (2017). Impact of digital marketing on sales growth of small and medium enterprises in Nairobi, Kenya. Unpublished MBA Research Project. University of Nairobi

Onyago K. (2016). Influence of digital marketing strategies on performance of cutflowers exporting firms in Kenya. Unpublished. MBA Research Project. School of Business, University of Nairobi

Parker, G, and Van Alstyne. (2011). A Digital Postal Platform: Definitions and a Roadmap. Massachusetts Institute of Technology, Working Paper.

Parveen, F., Jaafar, N. I., \& Ainin, S. (2016). Social media's impact on organizational performance and entrepreneurial orientation in organizations. Management Decision, 54(9), 2208-2234.

Pradiptarini, C. (2011). Social media marketing: Measuring its effectiveness and identifying the target market. $U W-L$ Journal of Undergraduate Research, 14, 1-12.

Roespinoedji, D., Faritzal, A., Sudrajat, A., Ahmed, U., \& Oktari, S. D. (2019). The Effect of HR Relational Strategy and Transactional Strategy on Supply Chain Performance: The Moderating Role of Environment Orientation. Int. J Sup. Chain. Mgt Vol, 8(2), 1-10.

Susan ward (2018). Marketing Practices of Selected Entrepreneurs in Ado-Odo Ota Local Government in Ogun state, Nigeria. Journal of Research in National Development 7(2), 197-204.

Tikkanen, H., Hietanen, J., Henttonen, T., \& Rokka, J. (2009). Exploring virtual worlds: success factors in virtual world marketing. Management Decision, 47(8), 1357-1381.

Yasmin, A., Tasneem S. \& Fatema. K. (2015). Effectiveness of Digital Marketing in the Challenging Age: An Empirical Study. International Journal of Management Science and Business Administration, 1(5), 69-80.

(C) 2020 by the author(s). Published by Annals of Contemporary Developments in Management \& HR (ACDMHR), under the terms and conditions of the Creative Commons Attribution (CC BY)

license which can be accessed at http://creativecommons.org/licenses/by/4.0. 